\title{
PROPOSTA DE REVITALIZAÇÃO NOS PROCESSOS DE COMUNICAÇÃO INTERNA: ESTUDO DE CASO NA EMPRESA JR LOG TRANSPORTES E LOGÍSTICAS
}

\section{ARTIGO ORIGINAL}

MARTINS, Brenda Brasil 1, ANDRADE, Eduarda Fernanda Gomes de 2, OLIVEIRA, Daniel Barroso de ${ }^{3}$, ROBERTO, José Carlos Alves ${ }^{4}$

MARTINS, Brenda Brasil. Et al. Proposta de revitalização nos processos de comunicação interna: estudo de caso na empresa Jr Log Transportes e Logísticas. Revista Científica Multidisciplinar Núcleo do Conhecimento. Ano 06, Ed. 05, Vol. 09, pp. 99-121. Maio de 2021. ISSN: 2448-0959, Link de acesso: https://www.nucleodoconhecimento.com.br/administracao/empresa-jr-log, $\quad$ DOI: 10.32749/nucleodoconhecimento.com.br/administracao/empresa-jr-log

\section{RESUMO}

A abordagem do conteúdo a ser apresentado busca demonstrar que, de forma estratégica, a revitalização nos processos de comunicação interna pode ser alcançada ao ser aplicada. O presente estudo surgiu a partir da verificação das áreas críticas efetuadas na empresa JR LOG transportes, que atua no segmento transportes em Manaus. Baseado nas informações da coleta de dados e análise do

\footnotetext{
${ }^{1}$ Graduanda do curso de Administração.

${ }^{2}$ Graduando do curso de Administração.

${ }^{3}$ Coorientador. Bacharel em Administração.

${ }^{4}$ Orientador. Mestrado profissional em Engenharia de produção. Especialização em Gestão em Logística empresarial. Graduação em Administração com Ênfase em Marketing.
}

$\mathrm{RC}: 85330$

Disponível em: https://www.nucleodoconhecimento.com.br/administracao/empresa-jr-log 
conteúdo, constatou-se menor desempenho no setor do $\mathrm{RH}$ em decorrência da falta da comunicação interna. O propósito do presente estudo é apresentar a comunicação interna e seu desempenho vital como ferramenta estratégica, focando no desenvolvimento e engajamento de seus clientes internos, e para tanto, apresenta os seguintes objetivos específicos: Possibilitar aos clientes internos o conhecimento das transformações ocorridas no seu local de trabalho; Tornar essencial a presença dos clientes internos no andamento dos negócios; Facilitar a comunicação interna, deixando-a clara e objetiva para o público interno. A criação dos indicadores para ações interventivas fez-se imprescindível, em razão da necessidade de um tratamento adequado da área crítica. Por essa razão foi-se necessário implementar a ferramenta $5 \mathrm{~W} 2 \mathrm{H}$, a fim de auxiliar na proposta da implementação dos seguintes atos de evolução: Analisar ruídos na comunicação, coordenar integração de todos os setores, aplicar ferramentas eficientes de comunicação, empregar colaboradores sem voz nem participação, categorizar feedbacks positivos e negativos. Após cumprimento da proposta, espera-se que a organização, dessa forma, melhore suas estratégias de relacionamento com sua equipe, visando o desenvolvimento de colaboradores eficientes, competentes e eficazes. Com pequenas mudanças dentro da organização é possível mudar o clima organizacional e, consequentemente, os resultados.

Palavras-Chave: Comunicação, Clientes Internos, Processos, Estratégias e Organização.

\section{INTRODUÇÃO}

Este artigo versa sobre um estudo de caso realizado na JR LOG Transportes, onde desempenhou estudos e análises através do desenvolvimento do diagnóstico, apontando a problemática da empresa e posteriormente sugerindo a recomendação de implementação/solução que a empresa necessita.

$\mathrm{RC}: 85330$

Disponível em: https://www.nucleodoconhecimento.com.br/administracao/empresa-jr-log 
Dessa forma, a presente pesquisa buscou avaliar o desempenho de diferentes setores de uma empresa do ramo de prestação de serviços logísticos. No estudo foi realizado o diagnóstico organizacional na empresa, que desempenha serviços de transportes, logística, manuseios e armazenagem de cargas, oferecendo para sua empresa a melhor alternativa de logística no tratamento da sua carga, com profissionais altamente qualificados, tudo para seu melhor atendimento e sua maior comodidade.

Através de análises feitas das áreas funcionais da empresa, constatou-se que a área de recursos humanos é a mais deficiente e mostra que há muitos pontos fracos que precisam ser melhorados, já que, a organização tem interferido de forma indireta a prestação de serviços aos clientes, já que a falha na comunicação interna e o alinhamento da equipe de trabalho, prejudica a comunicação interna da organização e a busca dos objetivos que abrange todas a práticas relacionadas ao comportamento dos colaboradores, orientando na direção dos seus objetivos e metas estipuladas para um bom funcionamento da organização proporcionando um ambiente adequado para todos da equipe.

Com isso, houve a necessidade de investir em meios de fortificar o diálogo interno e evitar que haja imperfeições nos próprios canais de transferência de informação é o princípio para quem quer ter mais efeitos com seus métodos, além disso influir de maneira positiva no próprio clima organizacional da firma, uma vez que simplificação a exclusão de ruídos e o envolvimento de empregados.

A comunicação interna é de suma importância para o desenvolvimento e a sobrevivência da organização. No decorrer dos anos tornou-se uma ferramenta estratégica, e com isso as empresas têm aumentado as suas preocupações com os seus funcionários.

$\mathrm{RC}: 85330$

Disponível em: https://www.nucleodoconhecimento.com.br/administracao/empresa-jr-log 
A finalidade desta pesquisa foi apresentar a comunicação interna e seu desempenho vital como ferramenta estratégica, focando no desenvolvimento e engajamento de seus colaboradores internos. Além disso, a pesquisa determina possibilitar aos clientes internos o conhecimento das transformações ocorridas no seu local de trabalho; tornar essencial a presença dos clientes internos no andamento dos negócios; facilitar a comunicação interna, deixando-a clara e objetiva para o público interno.

Sendo o Recursos Humanos $(\mathrm{RH})$ um dos setores mais importantes na gestão dos colaboradores buscando e facilitando no desempenho das organizações através de pessoas, a análise e desenvolvimento de profissionais nas organizações é de mérito para o crescimento no mercado. O estudo justifica-se pelo fato de a falha em que ruídos estão atrapalhando a transmissão das informações, que esse setor dispõe um papel fundamental em atuar de forma estratégica sendo um importante aliado nessa gestão, que envolve processos cruciais, como recrutamento e seleção, treinamento e desenvolvimento e gerenciamento de performance e além do relacionamento com os colaboradores.

\section{FUNDAMENTAÇÃO TEÓRICA}

Kleina (2014 p.48) afirma que a fundamentação teórica "tem duas funções principais: A primeira é a de contextualizar o leitor com os conceitos principais e necessários para o entendimento da pesquisa; e a segunda é servir como base para comparar a teoria com os resultados da pesquisa proposta."

A fundamentação teórica se baseia na pesquisa bibliográfica feita pelo pesquisador e que compreende a consulta de livros, periódicos à internet, sobre os assuntos abordados no trabalho em questão.

$\mathrm{RC}: 85330$

Disponível em: https://www.nucleodoconhecimento.com.br/administracao/empresa-jr-log 


\subsection{A IMPORTÂNCIA DA COMUNICAÇÃO INTERNA PARA AS ORGANIZAÇÕES}

Toda área de estudos com uma vertente profissional bastante acentuada, como é o caso da comunicação empresarial, defronta-se com o embate, às vezes insuperável, entre a teoria e a prática. Esse confronto se evidencia não só na ausência de alinhamento entre o que se postula como ideal e o que acontece na realidade, como também na leitura ou interpretação equivocada de conceitos em que se funda este campo de conhecimento. A comunicação empresarial tem sido, ao longo do tempo, pródiga nesses desvios exatamente porque as práticas profissionais insistem em destruir a consistência de um corpo teórico elaborado com muito esforço na academia. Uma visão imediatista e não comprometida em posturas éticas flexibiliza conceitos e redesenha processos com o intuito de atender os interesses comerciais, políticos ou mesmos pessoais, fazendo emergir uma comunicação empresarial sem identidade, não sintonizada com os desafios e valores do nosso tempo. (BUENO, 2014).

A comunicação surgiu como uma ótima maneira de poder se comunicar e tornou- se indispensável para nossas vidas, pois é uma fonte de entendimento, trabalho e diversão e torna-se gradativamente preciso acompanhar as novas tecnologias para se manter atualizado. A comunicação é o fator de maior complicação nos processos administrativos atuais. (SCHMIDT, 2014).

A comunicação é significante para os gestores e é necessária a todos os empregados. Dessa forma, a organização precisa propiciar um ambiente favorável a eficiência, atuação, inovação, criatividade e execução profissional de sujeitos e grupos. (TIBURCIO, 2013).

A realização da comunicação empresarial tem, sistematicamente, afrontado a noção de pluralidade ao propor e operacionalizar processos que estão comprometidos com

RC: 85330

Disponível em: https://www.nucleodoconhecimento.com.br/administracao/empresa-jr-log 
a simplificação, com a negação da complexidade. Isso ocorre particularmente com perspectiva que desconsidera a realidade de públicos múltiplos.

Verifica-se que a comunicação tal se tornou uma linguagem universal e novos canais de comunicação vão constantemente surgindo, moldando a vida dos indivíduos que estão cada vez mais inseridos em redes interativas. Neste sentido, denota-se que sociedade e revolução tecnológica estão muito relacionadas, caminhando sempre interligadas. (APARECIDA, 2015).

\subsection{COMUNICAÇÃO INTERNA NAS ORGANIZAÇÕES}

O desempenho da comunicação organizacional tem se caracterizado, em muitos casos, por equívocos espantosos no que diz respeito ao planejamento e execução de políticas e planos de comunicação interna. (BUENO, 2014).

Considera-se eficiente a comunicação, quando se definem objetivos claros, busca recursos humanos adequados às tarefas a serem executadas, empenha-se na motivação das pessoas, sabe buscar e compartilhar as estratégias mais adequadas visando atingir os objetivos esperados.

A comunicação é de suma importância para a organização sobreviver e ter um bom relacionamento com esses diferentes públicos, mas ela apenas se dá através do processo de interação que a empresa desenvolve. (BESSA et al, 2018).

No momento em que se vai comunicar algo a alguém, é essencial que se defina o conteúdo da conversa e a conclusão que se quer obter, porque, existe uma diferença entre comunicar e informar. Informar é somente transmitir a informação, não se sabe se o receptor obteve de forma correta e se ele compreendeu. Comunicar é o processo de troca de informações, é determinar uma comunicação entre duas ou mais pessoas. Afirmar que o recebedor, além de receber e compreender a mensagem, responde. (TIBURCIO, 2013).

$\mathrm{RC}: 85330$

Disponível em: https://www.nucleodoconhecimento.com.br/administracao/empresa-jr-log 
Diante deste contexto de transformação no mundo da comunicação, progressivamente mais pessoas podendo se comunicar e com o bombardeamento de mensagens ao redor delas, o processo comunicacional nas organizações tende a passar por uma reconfiguração, para se adaptar a essas mudanças e novas demandas, buscando outras estratégias para atingir seu público e captar sua atenção. (APARECIDA, 2015).

\subsection{FUNÇÕES DA COMUNICAÇÃO INTERNA}

A comunicação tem quatro finalidades essenciais dentro de um grupo ou no meio de uma organização: controle, motivação, expressão emocional e informação. (ROBBINS, 2015). A comunicação organizacional evoluiu tanto que as empresas passaram a ter uma visão de forma estratégica, isto é, se tornou um componente fundamental para as organizações.

Portanto, um dos primordiais problemas enfrentados pelas empresas atualmente, quando se fala em comunicação, é a insuficiência de feedback (resultado). É esse processo que afirma as conclusões e o fluxo das mensagens com êxito.

A necessidade do retorno, os ruídos que ocorrem no meio, fazem com que a comunicação se torne ineficiente. Portanto uma comunicação eficiente é aquela que transforma as ações das pessoas. Se somente modifica as ideias, mas não modifica suas atitudes, então ela não obteve resultado. Para que tenha êxito na divulgação de informações, os canais formais de comunicação precisam ser claros; consistentes; contínuos e frequentes. (TIBURCIO, 2013).

Observa-se que grande parte do sucesso da estratégia de comunicação de uma empresa depende da conexão entre a estratégia de comunicação e a estratégia geral da empresa. Torna-se indispensável ter um sólido desempenho da comunicação empresarial para apoiar tais missões e visão.

RC: 85330

Disponível em: https://www.nucleodoconhecimento.com.br/administracao/empresa-jr-log 
Contudo, este processo não pode ser função deste ou daquele setor. É função de todos. Tiburcio (2013) diz que todos devem estar alinhados com o planejamento estratégico. O funcionário deve saber a importância do lugar onde trabalha e da sua própria importância.

$\mathrm{Na}$ atualidade a comunicação interna está maior e mais complexa pelo motivo de que dentro de uma organização existem públicos diferentes. E, por este motivo, as empresas têm que apostar em uma boa comunicação, para evitar o famoso telefone sem fio. Por essa razão a comunicação interna consiste em deixar todos da organização alinhados com os processos, os objetivos, as estratégias, os valores e as metas da empresa. (FERNANDES, 2020).

Acontece, várias vezes, é que, um colaborador desmotivado é "um barco à deriva". Que não se empenha pelo seu desenvolvimento profissional, atrapalha o desenvolvimento dos outros colaboradores e da empresa. Logo, é necessário aperfeiçoar a comunicação organizacional com seus funcionários e entre os próprios funcionários com o propósito de alcançar a qualidade das informações e maior produtividade.

A Comunicação interna é um setor, ou os esforços, concentrados em garantir um bom relacionamento e ajuste entre uma organização e seus colaboradores. Deste modo, a comunicação interna permite que a empresa trabalhe de forma integrada, promovendo maior produtividade, engajamento e resultados. Acredita-se que a comunicação interna em uma organização é um processo extenso, que tem como objetivo provocar atitudes, sendo elas voluntárias ou não por parte dos públicos que a recebem, isto é, os públicos para os quais a empresa se dirige e visa estabelecer a reputação da organização. (GOULART, 2015).

RC: 85330

Disponível em: https://www.nucleodoconhecimento.com.br/administracao/empresa-jr-log 
Compreende-se que nenhuma dessas funções é mais importante que as demais. Todas são fundamentais, são interligadas, têm que funcionar instantaneamente para que ocorra progresso no desenvolvimento e realização das atividades realizadas.

\subsection{PROCESSOS DE COMUNICAÇÃO}

Ao trabalhar com a comunicação no âmbito de trabalho diariamente, a integração entre colaboradores aumenta e auxilia no sucesso dos projetos e entendimento das informações. $E$ as ações feitas com o público interno refletem diretamente no público externo e, certamente, influenciará no posicionamento da empresa no mercado. (BESSA et al, 2018).

As fases de comunicação são a transmissão de informação e de sentidos, porque sem eles não há conversa eficaz dentro da organização. Já no campo de marketing para se ter um programa eficiente de diálogo, o profissional da área deve conhecer o método de conversa, para compreender o que a comunicabilidade causa aos seus clientes, possuindo assim novos e bons efeitos.

De acordo com Silva (2013) os componentes que constituem o processo de comunicação são apresentados e definidos a seguir:

- A fonte de informação: que produz a mensagem ou a sequência de mensagens que serão comunicadas;

- O transmissor: que transforma a mensagem em sinal adequado ao canal;

- O canal: é usado para transmitir o sinal do transmissor ao receptor;

- O receptor: converte o sinal que foi recebido em mensagem e envia ao destinatário;

- O destinatário: é o indivíduo a qual a mensagem é

RC: 85330

Disponível em: https://www.nucleodoconhecimento.com.br/administracao/empresa-jr-log 
Observa-se que esta forma é o que delimita o receptor do destinatário, tendo em vista como algo que refaz a mensagem a começar dos sinais recebidos.

A figura 1 mostra os elementos que compõem o processo de comunicação:

Figura 1 - Processo De Comunicação

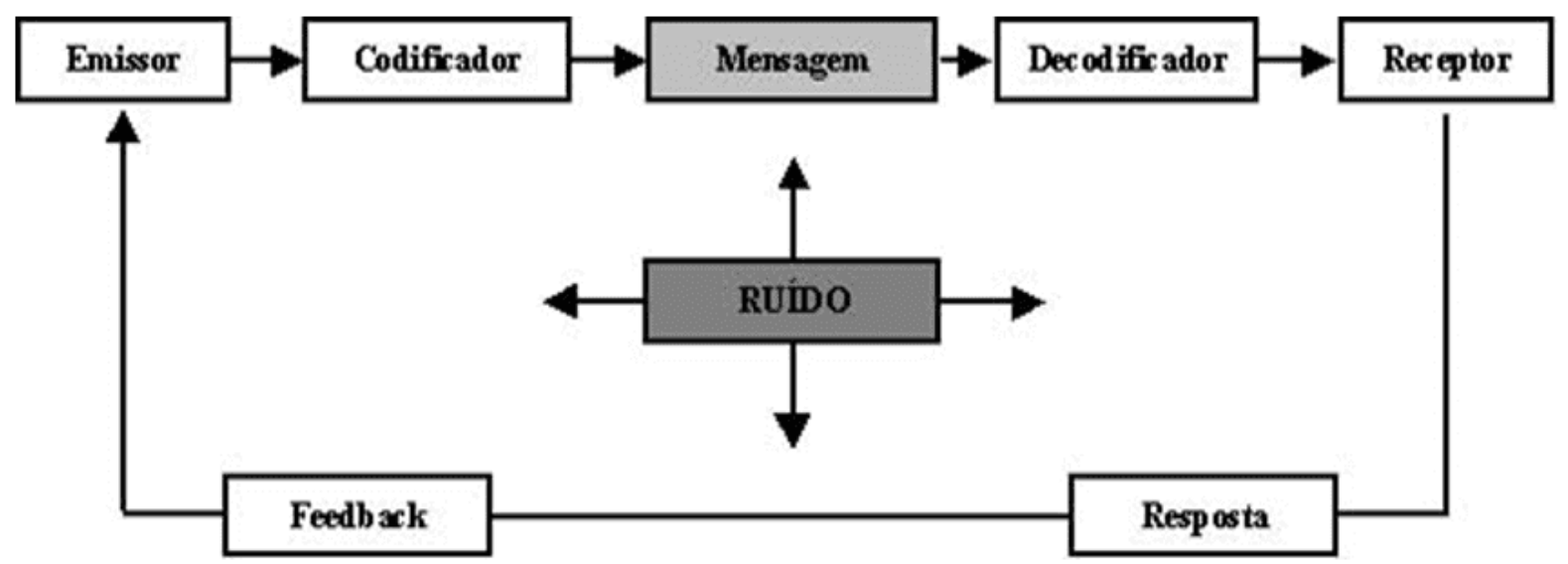

Fonte: Kotler, 2014, p. 571.

Porém, no processo de comunicação sofre-se também ruídos que podem provocar perdas ou desvios na mensagem que prejudicam o entendimento ou a interferência, essa que pode provocar distorção na mensagem transmitida.

No entanto, geralmente aquilo que o emissor planeja comunicar ao seu destinatário é o que ele realmente interpreta e compreende, desse modo é indispensável que se utilize um meio de transmitir a mensagem almejada utilizando um conteúdo que todos possam compreender.

\subsection{FLUXOS DE COMUNICAÇÃO}

Considera-se que a transmissão de uma mensagem é elaborada através de processos, logo esta é composta por vários tipos de como deve e pode ser transmitida. Segundo Cruz (2016) são os chamados fluxos de comunicação, estes

RC: 85330

Disponível em: https://www.nucleodoconhecimento.com.br/administracao/empresa-jr-log 
fluxos são a classificação de como a informação está sendo passada, e como o receptor recebe a mensagem.

Desta forma, segundo Matos (2014), existem cinco fluxos que integram as maneiras e formas que a comunicação pode ser propagada dentro das organizações:

1. Descendente: É uma comunicação vertical, sendo de cima para baixo. Este fluxo representa a transmissão de informações do topo para a base, ou seja, é quando alguém de uma posição superior apresenta uma informação para alguém de posição inferior.

2. Ascendente: $O$ fluxo da comunicação ascendente transmite informações da base da empresa até a cúpula. Nisto, podemos citar como exemplo um colaborador que envia um e-mail para seu gerente, manifestando uma comunicação para

3. Horizontal: É uma comunicação horizontal ou lateral, pois é quando se transmite informações no meio de integrantes do mesmo grupo, sendo do mesmo nível hierárquico, que se comunicam de forma que seja diagonal ou lateral.

4. Transversal: É um fluxo que se faz presente tanto na comunicação ascendente e descendentes e nos mais variados níveis da organização. Neste tipo de comunicação acontece nas organizações mais flexíveis que permitem a gestão organizacional mais participativa, ocasionando com que as pessoas passem a influir em diversas áreas e com isso passam a interagir.

5. Circular: Neste tipo de fluxo de comunicação a transmissão das informações fluem entre todos sem algum tipo de regra específica. Neste caso, a hierarquia não interfere no fluxo da

$\mathrm{RC}: 85330$ 
comunicação. Este tipo de comunicação é observado geralmente nas pequenas

Observou-se os fluxos mencionados acima, servem para orientar o fluxo da comunicação e potencializar a transmissão da informação sendo ela formal ou informal. Todos os fluxos têm a sua importância no meio da organização e são capazes de contribuir para o crescimento da mesma.

\subsection{BARREIRAS À COMUNICAÇÃO}

No momento em que a comunicação não é estabelecida de um formato claro e objetivo, há a dificuldade em estabelecer objetivos entre os grupos de colaboradores, pois os objetivos só podem ser atingidos quando efetivamente a comunicação torna-se comum.

As chamadas barreiras de comunicação interferem, geram bloqueios e criam restrições que são interpostas entre os emissores e receptores. Esses obstáculos são geralmente restrições ou limitações que podem ocorrer através das fases do processo de comunicação fazendo com que a mensagem chegue distorcida, sobre as alterações tanto para minimizar o conteúdo como na sua maximização (SCHMIDT, 2014).

Isso faz com a mensagem enviada pelo remetente chegue ao receptor diferente e dessa forma, seja interpretada não da forma ideal, como planejado no início do processo de comunicação.

A comunicação é uma ação que possibilita a troca de mensagens entre as pessoas, que estimula e intenciona 0 ato de se comunicar, verifica-se desde cedo a necessidade de comunicação para inserção nas relações sociais e dentro das organizações. Entende-se grande parte do tempo e nem sempre as informações são

RC: 85330

Disponível em: https://www.nucleodoconhecimento.com.br/administracao/empresa-jr-log 
compreendidas como deveriam ser, pois ocorrem ruídos na interpretação ou na emissão da mensagem. (CRUZ, 2016).

No âmbito de uma organização, o processo de comunicação acontece tanto no sentido vertical como sentido horizontal, ou seja, a organização é uma verdadeira rede de informações que se transita. Desta forma, os boatos raramente deixaram de existir internamente nas organizações, pois é um fluxo de comunicação interna utilizado para ficarem por dentro do que ocorre no direcionamento da organização.

Esse ruído é bastante comum quando um superior se comunica com um funcionário por e-mail. Normalmente, o grau de intimidade entre eles é menor, fazendo com que os colaboradores interpretem o pior da mensagem. (FERNANDES, 2020).

Hoje em dia utiliza-se a tecnologia para girar as informações informais dentro das organizações, tendo como exemplo, o WhatsApp, com o de agilizar a comunicação e auxiliar nas atividades.

\section{MATERIAIS E MÉTODOS}

Metodologia é a definição dos procedimentos técnicos, das modalidades de atividades, dos métodos que serão utilizados na pesquisa. Vai depender da natureza do trabalho, do tipo de pesquisa e dos objetivos propostos.

Para Fonseca (2012, p. 19) "O método, portanto, constitui um dos pontos centrais nas formas de conhecimento do ser humano. Ao levarmos esse conceito para a aquisição do conhecimento em ciência, teremos um método chamado científico".

Mediante isso o estudo quanto a metodologia deste trabalho terá como suporte diversificados tipos de pesquisas e fundamentos, a fim de aperfeiçoar e detalhar os principais pontos a serem averiguados.

RC: 85330

Disponível em: https://www.nucleodoconhecimento.com.br/administracao/empresa-jr-log 


\subsection{PROCEDIMENTOS METODOLÓGICOS}

Chemin (2015 p. 53) afirma que os procedimentos metodológicos

há inúmeros procedimentos metodológicos (caminhos, métodos, normas, regras, padrões, modos, protocolos, materiais que serão adotados para alcançar determinado objetivo), ou seja, a melhor forma de investigar, de buscar soluções para os problemas está no estudo e na aplicação de modelos de pesquisas que já demonstraram consistência teórica e prática.

O presente projeto resultou-se por meio de pesquisas bibliográficas e coleta de dados, tendo como objetivo identificar artigos e livros sobre o tema abordado com o propósito de detectar os possíveis erros na comunicação interna, introduzindo maneiras que melhor se adequam à necessidade da instituição de acordo com a problemática percebida, levando em consideração os que ela já utiliza.

\subsubsection{QUANTO À NATUREZA}

Para Fleury e Werlang (2017) a pesquisa aplicada concentra-se em torno dos problemas presentes nas atividades das instituições, organizações, grupos ou atores sociais. Para engrandecer esse tipo de pesquisa, com base nas hipóteses já formuladas ou reformuladas, será feito um diagnóstico identificando os principais problemas e buscando soluções.

Desse modo, a abordagem adotada ao estudo em questão é a qualitativa em função da busca de analisar, desenvolver e investigar os processos relacionados ao foco do tema abordado. A natureza da pesquisa utilizada será aplicada onde será possível aplicar o instrumento na empresa em estudo.

RC: 85330

Disponível em: https://www.nucleodoconhecimento.com.br/administracao/empresa-jr-log 


\subsubsection{QUANTO AOS FINS}

Quanto aos fins da pesquisa é exploratória. Mello (2013 p.45) diz que "a pesquisa exploratória visa obter maior familiaridade com o problema para torná-lo explícito ou a construir hipóteses e aplicada em áreas nas quais há pouco conhecimento, explora a realidade buscando embasamento para depois planejar uma pesquisa descritiva."

Para aplicação desse tipo de pesquisa será utilizado um roteiro de entrevista com perguntas abertas para coletar dados referente a comunicação da organização.

\subsubsection{QUANTO AOS MEIOS}

No que se refere aos meios, o foco será pesquisa bibliográfica e estudo de caso. De acordo com Pizzani et al. (2013) a pesquisa bibliográfica é um trabalho investigativo minucioso em busca do conhecimento e base fundamental para o todo de uma pesquisa.

Para fins de obter resultados de pesquisa de uma única empresa por meio da coleta de dados adotou-se o estudo de caso para tornar as informações aprofundadas e publicadas cientificamente e bibliográfica como base e reforço através das plataformas Google Acadêmico, Scielo (Scientific Electronic Library Online), Biblioteca Virtual da FAPESP e BDTD (Biblioteca Digital de Teses e Dissertações). Serão selecionados artigos relevantes via leitura dos títulos e resumos a partir das palavras chaves: Comunicação, Liderança e Cultura Organizacional, utilizando filtros da área de conhecimento, país e idioma e será baseado em Pesquisa de Campo, a qual já vem sendo trabalhada desde o Diagnóstico Organizacional no ano de 2020.

RC: 85330

Disponível em: https://www.nucleodoconhecimento.com.br/administracao/empresa-jr-log 


\subsection{CARACTERIZAÇÃO DA EMPRESA: J R LOG TRANSPORTES E LOGÍSTICA}

A empresa J R LOG Transportes e Logística Eireli LTDA-ME, CNPJ:84.462.100/0001-20, fundada em 1993, na cidade de Manaus - Amazonas, de nome fantasia J R LOG TRANSPORTES e LOGÍSTICA, de forma jurídica, sede administrativa na Rua Maria Andrade, 875, Bairro: São Lázaro - CEP 69073-479.

A empresa começou em 1993 com o nome Rosemberg de Andrade Souza EIRELIME, onde o empresário e diretor era apenas autônomo e fazia alguns serviços. Em 2012 foi quando decidiu abrir a empresa física começando apenas com uma sala, uma empresa pequena, um funcionário, um assistente administrativo, cuidando dos processos de transporte e fazendo serviços com terceirizados, pois ele ainda não tinha caminhões.

Em 2014 começou a ter a sua própria Frota, mudou a sua razão social para JR LOG TRANSPORTE E LOGÍSTICA EIRELI-ME e mudou-se para um espaço maior, localizado no endereço Rua Presidente Coimbra da luz, N 05 - Central Parque, 4⿻ etapa - Flores com salas e um espaço externo grande para os caminhos e porta contêiner, seu número de funcionários aumentou, 1 diretor, 2 administrativos, 1 financeiro, 4 motoristas. Ele passou a ter mais cargas para coletar e transportar.

Em 2018 o espaço da empresa começou a ficar pequeno para o número de caminhões e porta contêineres que existia na empresa, então ele optou por se mudar para um espaço maior onde a sala é menor e o Espaço externo maior, no endereço rua Maria Andrade 875 - crespo. Pois a sua frota aumentou novamente, hoje ele tem seis caminhões, 10 porta contêiner de 20 e 10 porta contêiner de 40 e aumentou também o quadro de funcionários, hoje ele tem dentro da empresa 1 Diretor, 1 financeiro, 3 administrativos, 2 operacional e 6 motoristas. Tem como benefício carteira assinada, vale refeição e vale transporte. Alguns Clientes são a

RC: 85330

Disponível em: https://www.nucleodoconhecimento.com.br/administracao/empresa-jr-log 
bemol, Ramsons, TV Lar etc. e alguns dos concorrentes são a Thiba, Dulmport e Grampor.

A empresa tem como atuação principal: Transporte rodoviário de carga, exceto produtos perigosos e mudanças, intermunicipal, interestadual e internacional. J R LOG Transportes e Logística é uma empresa prestadora de soluções logísticas, oferecendo assessoria e desenvolvimento de projetos personalizados, este serviço possibilita ao cliente optar por uma cadeia de logística integrada atrativa e com melhor custo-benefício, com especialização em Cabotagem e rastreamento 24 horas para garantir o cumprimento dos prazos de entrega.

\section{RESULTADOS E DISCUSSÕES}

Com fundamento em estudos e pesquisas de campo realizados na etapa do diagnóstico Organizacional I, foi averiguado a média de desempenho das áreas funcionais da empresa JR LOG Transportes e Logística sendo elas: Marketing, Produção e Operações, Finanças, Recursos Humanos, Administração e Logística.

Conclui-se com base na pesquisa desempenhada, nos dias de hoje, que qualquer organização que utiliza a comunicação como uma ferramenta estratégica, está alinhada aos requisitos exigidos do mercado competitivo, sendo capaz de atender as necessidades do cliente.

\subsection{GRÁFICO DA ÁREA CRÍTICA}

De acordo com o gráfico 01 o atributo de recursos humanos, apresenta um número alto de inconsistências como pontos a melhorar e ponto fraco, isso requer necessidade de uma maior atenção. As empresas que contam com um departamento de $\mathrm{RH}$, agregam valor e demonstram mais status e confiança para seu cliente, tendo em vista que contam com um departamento específico para cuidar, supervisionar e motivar os seus funcionários.

RC: 85330

Disponível em: https://www.nucleodoconhecimento.com.br/administracao/empresa-jr-log 
Gráfico 01 - Desempenho Por Área Funcional

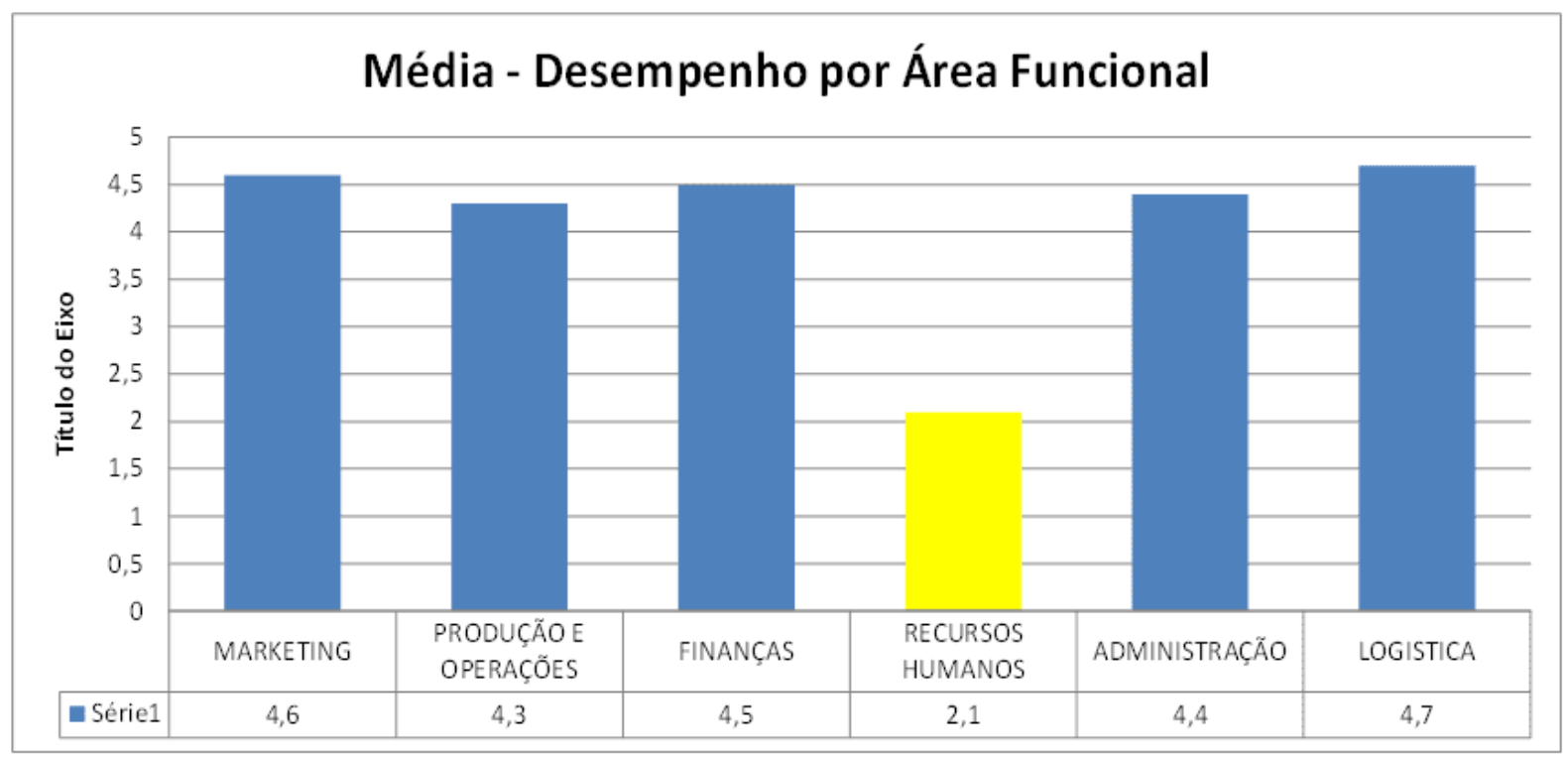

Fonte: Martins e Andrade 2020.

\subsection{QUADRO DA ÁREA MAIS CRÍTICA}

O Departamento de Recursos Humanos exerce um papel fundamental em uma empresa, sendo um elo entre funcionários e diretoria. Tendo como função motivar o funcionário, mostrando que o local onde trabalha é bom para se trabalhar, e apontar a quando um colaborador se destaca ou necessita de auxílio e capacitação em algum aspecto. $\mathrm{O}$ quadro 01 mostra como foram avaliados o setor de recursos humanos da empresa estudada.

Quadro 01 Área Funcional Crítica - Recursos Humanos

\section{ÁREA FUNCIONAL}

RECURSOS HUMANOS
NÍVEL OU GRAU DE AVALIAÇÃO

\begin{tabular}{|l|l|l|l|l|} 
Ponto & Ponto & $\begin{array}{l}\text { Ponto } \\
\text { médio 3 }\end{array}$ & Ponto & Ponto \\
muito & forte & & fraco & muito
\end{tabular}

RC: 85330

Disponível em: https://www.nucleodoconhecimento.com.br/administracao/empresa-jr-log 


\begin{tabular}{|c|c|c|c|c|c|c|}
\hline & & forte 5 & 4 & & 2 & $\begin{array}{l}\text { fraco } \\
1\end{array}$ \\
\hline 1 & Canal de comunicação definido & & & & $x$ & \\
\hline 2 & Integração de todos os setores & & & $x$ & & \\
\hline 3 & Ruídos na comunicação & & & & & $x$ \\
\hline 4 & Linguagem adequada & & & & $x$ & \\
\hline 5 & $\begin{array}{l}\text { Ferramentas eficientes de } \\
\text { comunicação }\end{array}$ & & & & $x$ & \\
\hline 6 & $\begin{array}{l}\text { Feedbacks positivos e } \\
\text { negativos }\end{array}$ & & & & & $x$ \\
\hline 7 & $\begin{array}{l}\text { Conhecimento sobre o público } \\
\text { interno }\end{array}$ & & & & $x$ & \\
\hline 8 & $\begin{array}{l}\text { Colaboradores sem voz nem } \\
\text { participação }\end{array}$ & & & & & $\mathrm{x}$ \\
\hline 9 & Líderes despreparados & & $x$ & & & \\
\hline 10 & Aumento de Turnover & & & $\mathrm{x}$ & & \\
\hline TO & $\mathrm{TAL}(\Sigma)$ & 0 & 4 & 6 & 8 & 3 \\
\hline $\begin{array}{l}\text { MÉ } \\
\text { CO }\end{array}$ & $\begin{array}{l}\text { DIA POR GRAU } \\
\text { LUNA) }\end{array}$ & 0 & 0,4 & 0,6 & 0,8 & 0,3 \\
\hline DE & SEMPENHO DA ÁREA & 2,1 & & & & \\
\hline
\end{tabular}

Fonte: Martins e Anrade, 2020.

E com base nessa análise foi detectado que a comunicação interna é o principal problema. A comunicação interna fez-se peça crucial no processo de integração no ambiente das organizações. No decorrer do tempo, os processos de comunicação foram ganhando espaço e credibilidade, evidenciando a comunicação interna como uma arma poderosa se usada de forma eficiente no âmbito da organização. Nesta

RC: 85330

Disponível em: https://www.nucleodoconhecimento.com.br/administracao/empresa-jr-log 
sequência, destaca-se que os avanços tecnológicos surgiram como um grande aliado na propagação de mensagens e valores para o público interno de uma organização.

\subsection{PLANEJAMENTO DE AÇÕES}

O quadro 2 apresenta uma proposta de melhoria para o departamento de recursos humanos da JR Log Transportes e Logística voltado para a comunicação interna, sendo 05 ações que começarão a ser implementadas em maio de 2021 e com final previsto para fevereiro de 2022. Todos a serem realizados por uma empresa especializada em Consultoria Empresarial. Sendo esta apresentada em nossa proposta para formulação e levantamento de custos.

Quadro 02 - Ações Interventivas

\begin{tabular}{|c|c|c|c|c|}
\hline $\mathrm{N}^{0}$ & Açoes Interventivas & Cronologia & Duração & Custo \\
\hline 1 & Ana lisar núdos na commuicação & mi/21 & 5 dias & $\mathrm{R} \$ 500,00$ \\
\hline 2 & Coordenar integracão de todos os setores & $\mathrm{j} w / 21$ & 15 dias & $\mathrm{R} \$ 1.500,00$ \\
\hline 3 & Ap licar ferramentas eficientes de commicação & $\mathrm{ju} / 21$ & 10 dias & $R \$ 1.000,00$ \\
\hline 4 & Empregar colaboradores sem voz nem particịação & $\operatorname{ag} 0 / 21$ & 5 dias & $\mathrm{R} \$ 500,00$ \\
\hline 5 & Categorizar feedbacks positivos enegativos & $\operatorname{set} / 21$ & 30 dias & $\mathrm{R} \$ 3.000,00$ \\
\hline
\end{tabular}

Fonte: Martins e Anrade, 2021.

A comunicação nas organizações vai depender da qualidade da comunicação pessoal e interna, ou seja, se as pessoas dentro da organização se comunicam de forma correta. Um dos maiores propósitos da comunicação interna de uma empresa

RC: 85330

Disponível em: https://www.nucleodoconhecimento.com.br/administracao/empresa-jr-log 
é a capacidade de alinhar a equipe de trabalho, preparando todo o grupo de colaboradores para uma mesma direção e almejando os mesmos objetivos.

\subsubsection{ANALISAR RUÍDOS NA COMUNICAÇÃO}

Os ruídos na comunicação podem causar problemas grandiosos a empresa e queda em seus resultados. Espera-se que diminua a insatisfação dos clientes, melhorando os processos, melhoria na gestão, aumento na produtividade, treinamentos apropriados e repasse de mensagens coesas. Aponta-se que a eficácia da comunicação organizacional é influenciada pelos ruídos existentes dentro da empresa, é assim criando barreiras nas transmissões das mensagens.

No quadro 3 detalha-se ação que visa categorizar os tipos de ruído existentes na organização visto que se faz necessário construir um solida proposta de solução.

Quadro 03 5w2h - Analisar Ruídos Na Comunicação

\begin{tabular}{|c|l|}
\hline Meta 1 & Analis ar ruídos na comunicação \\
\hline O quê? & Ruídos na comunicação \\
\hline Por quê? & Para reduzir resultados negativos \\
\hline Onde? & JRLOG Logística e Transportes \\
\hline Quando? & Na primeira semana do mês de Maio de 2021 \\
\hline Quem? & JGC Consultoria \\
\hline Como? & Destacando principais pontos que contribuem para uma comunicação ruim \\
\hline Quanto? & R\$ 500,00 \\
\hline & \\
\end{tabular}

Fonte: Martins e Anrade, 2021.

RC: 85330

Disponível em: https://www.nucleodoconhecimento.com.br/administracao/empresa-jr-log 
Entende-se que esta etapa do projeto de implementação será de fundamental importância, à empresa de consultoria contratada irá mapear os tipos de ruídos dentre a categorias Físico, fisiológico, psicológico e semântico e a partir dos resultados mapeados traçarem a luz da bibliografia a melhor estratégia que possa resolver os problemas de ruído na comunicação da organização.

Objetiva-se com esta ação manter um ambiente colaborativo e saudável para os envolvidos nos processos internos e externos da empresa estudada, proporcionando assim obtenção de ganhos operacionais.

\subsubsection{COORDENAR INTEGRAÇÃO DE TODOS OS SETORES}

Quando os colaboradores e gestores têm momentos de integração durante suas rotinas diárias, os ruídos de comunicação perdem força. Sendo em alguns minutos depois do almoço e ou no intervalo do café. O importante é que interajam entre si. Espera-se que com isso se fortaleça os relacionamentos, melhore o clima organizacional e identifique com mais agilidade as situações que podem gerar problemas.

Quadro 04 5w2h - Coordenar Integração De Todos Os Setores

\begin{tabular}{|c|l|}
\hline Meta 2 & Coordenar integracão de todos os setores \\
\hline O quê? & Integração dos setores \\
\hline Por quê? & Para melhorar o engajamento entre os setores \\
\hline Onde? & JR LOG Logística e Transportes \\
\hline Quando? & Na primeira semana do mês de Junho de 2021 \\
\hline Quem? & JGC Consultoria \\
\hline Como? & Comunicar de forma clara e ouvir com atenção \\
\hline Quanto? & R\$ 1.500,00 \\
\hline & \\
\hline
\end{tabular}

Fonte: Martins e Anrade, 2021.

RC: 85330

Disponível em: https://www.nucleodoconhecimento.com.br/administracao/empresa-jr-log 
Indica-se a prática de integração entre os setores na busca de se estabelecer um equilibrado ambiente dentro da organização. Objetivando-se criação de planos conjuntos que busquem resultados coletivos na empresa, ou seja, uma ação conjunta entre setores pode eliminar barreiras e reduzir as dificuldades de execução das metas organizacionais.

E fundamental que se estabeleça o diálogo visto que todo processo de mudança causa descontentamento e resistência, porém estas adversidades permitem o surgimento de estratégias mais construtivas e mais integradas e que se estabeleça a rotina de melhoria contínua nos processos da empresa por meio desta prática.

\subsubsection{APLICAR FERRAMENTAS EFICIENTES DE COMUNICAÇÃO}

Se a empresa não tem canais de comunicação definidos, qualquer boato ganha força e se espalha com facilidade dentro da organização. Podendo ocasionar mesmo que acidentalmente rumores no âmbito da organização. Espera-se que com isso se possa garantir que o público interno esteja bem-informado sobre tudo que acontece na empresa. E assim se evitar especulações e fofocas, grandes inimigas da produtividade.

Quadro $055 w 2 h$ - Aplicar Ferramentas Eficientes De Comunicação

\begin{tabular}{|c|l|}
\hline Meta 3 & Aplicar ferramentas eficientes de comunicação \\
\hline 0 quê? & Ferramentas eficientes de comunicação \\
\hline Por quê? & Para promover sinergia e alcançar melhores resultados \\
\hline Onde? & JR LOG Logísica e Transportes \\
\hline Quando? & Na primeria semana do mês de Julho de 2021 \\
\hline Quem? & JGC Consultoria \\
\hline Como? & Definir quais canais de comunicação intema serão utilizados \\
\hline Quanto? & R\$1.000,00 \\
\hline & \multicolumn{2}{|l}{} \\
\hline
\end{tabular}

Fonte: Martins e Anrade, 2021.

RC: 85330

Disponível em: https://www.nucleodoconhecimento.com.br/administracao/empresa-jr-log 
A empresa de consultoria irá introduzir em um primeiro momento as ferramentas de caixa de sugestões, mural de recados, intranet e vídeo corporativo decisão está tomada em consultoria e empresa baseando-se no critério de custo benéfico.

Entende-se que por se tratar de uma nova prática e se utilizando das experiências anteriores da consultoria que na primeira fase deste projeto este conjunto de ações já poderá surtir efeitos imediatos na construção de uma estratégia eficiente de comunicação.

\subsubsection{EMPREGAR COLABORADORES SEM VOZ NEM PARTICIPAÇÃO}

Quando se deixa bem claro a importância do colaborador para os resultados da organização, ele trabalha muito mais motivado e engajado. E o risco de erros e falhas passa a ser mínimo possível. Espera-se manter os colaboradores beminformados sobre tudo que acontece na empresa, investimentos em desenvolvimento profissional podem ser feito, definição de tarefas e metas de cada um sempre incentivando o trabalho em equipe.

Quadro 06 5w2h - Empregar Colaboradores Sem Voz Nem Participação

\begin{tabular}{|c|l|}
\hline Meta 4 & Empregar colaboradores sem voz nem participação \\
\hline O quê? & Colaboradores sem voze participação \\
\hline Por quê? & Para se ter a confiança e o comprometimento do público interno \\
\hline Onde? & JR LOG Loǵsictica e Transportes \\
\hline Quando? & Na primeira semana do mês de Agosto de 2021 \\
\hline Quem? & JGC Consultoria \\
\hline Como? & Manter os fincionários por dentro das novidades boas e ruins da empresa \\
\hline Quanto? & R\$ 500,00 \\
\hline & \\
\hline
\end{tabular}

Fonte: Martins e Anrade, 2021.

RC: 85330

Disponível em: https://www.nucleodoconhecimento.com.br/administracao/empresa-jr-log 
Observa-se que nas empresas que há gestão participativa os resultados tendem a ser mais eficientes do ponto de vista de agilidade e de custos operacionais. Ninguém conhece mais os problemas da empresa que os próprios funcionários e sabias são as empresas que se utilizam deste capital intelectual para aprimorar seus processos internos

Entende-se que o processo de engajamento obtido com a gestão participa justifica esta ação que faz com que os colaboradores passem a ter a sensação de participar de um time e buscam continuamente estudar melhorias de processo e de capacitação necessários ao desenvolvimento da empresa

\subsubsection{CATEGORIZAR FEEDBACKS POSITIVOS E NEGATIVOS}

Constata-se que a prática do feedback pode ser um fator impulsionador de crescimento e direcionamento ao desenvolvimento dos colaboradores já que direciona os colaboradores a melhorar de acordo com o que se espera pela gestores e assim desenvolver sua capacidade técnica operativa alinhados aos objetivos da empresa.

Avaliar e opinar sobre o trabalho dos colaboradores pode ajudá-los no aperfeiçoamento de seus procedimentos. Cabe à organização também saber ouvir críticas e opiniões sobre seus processos é igualmente importante para o desenvolvimento profissional e crescimento da organização.

RC: 85330

Disponível em: https://www.nucleodoconhecimento.com.br/administracao/empresa-jr-log 


\section{Quadro 07 5w2h - Categorizar Feedbacks Positivos E Negativos}

\begin{tabular}{|c|l|}
\hline Meta 5 & Categorizar feedbacks positivos e negativos \\
\hline O quê? & Feedbacks positivos e negativos \\
\hline Por quê? & Para manter os colaboradores engajados e cientes do que se espera deles \\
\hline Onde? & JRLOG Logística e Transportes \\
\hline Quando? & Na primeira semana do mês de Setembro de 2021 \\
\hline Quem? & JGC Consultoria \\
\hline Como? & Realizaç̃a de reuniões de alinhamento de equipe \\
\hline Quanto? & R\$ 3.000,00 \\
\hline & \\
\hline
\end{tabular}

Compreende-se que a introdução da cultura do feedback e um instrumento eficaz no sentido de proporcionar benefícios diversos a organização. Destacam-se entre estes benefícios o aprendizado contínuo necessário ao desenvolvimento individual e corporativo, melhora do desempenho motivada pela transparência no relacionamento líder / liderado e motivação dos colaboradores que passam a ter o sentimento de ser um ator principal na consecução dos resultados organizacionais.

A eficácia da introdução da prática de feedback dever ser construída de forma estruturada e muito bem divulgada e compreendida pelos colaboradores a fim de proporcionar crescimento contínuo da organização e dos colaboradores. E fundamental que não se use a ferramenta como instrumento punitivo para não causar deturpação dos resultados ocasionando ineficácia no processo.

RC: 85330

Disponível em: https://www.nucleodoconhecimento.com.br/administracao/empresa-jr-log 


\section{CONSIDERAÇÕES FINAIS}

De acordo com os aspectos estudados, foi possível constatar a importância da comunicação interna como estratégia de gestão das organizações. Identificamos no assunto pesquisado, que sem uma comunicação interna eficiente, as organizações não são capazes de atingir seus objetivos. Em efeito disso, nos últimos anos, ela passou a ser considerada de essencial necessidade para as organizações, sua importância é fundamental, tanto que essa ferramenta vem sendo considerada e prestigiada como vantagem competitiva.

Muitos são os fatores propícios para o desenvolvimento de uma organização, mas um dos mais importantes, sem dúvida, é o diálogo. Ferramenta de máxima importância e necessidade seja qual for sua área de atuação, dado que, o sucesso de uma empresa e o cuidado de funcionários ainda está ligado em uma segura comunicação interna, conduzindo a lealdade e a produtividade da força de trabalho. Ela é o fator decisório do seu êxito ou reprovação junto ao cliente final, seja o cliente interno ou externo.

Diante dessa necessidade, empresas bem-sucedidas buscam um diálogo mais assertivo. Muito diferente do que se via em algumas décadas atrás. Hoje essa comunicação não é mais apontada somente ao público externo (clientes finais), mas também ao público interno, ou melhor, seus colaboradores.

Para que se tenha êxito na comunicação é essencial que a diretoria da organização também esteja disposta a ouvir seus colaboradores e a manter uma conversa aberta, permitindo o feedback contínuo entre todas as partes interessadas.

Com algumas mudanças dentro da organização é possível mudar o clima organizacional e dessa maneira alterar os resultados. Quanto mais um colaborador se sentir relacionado e acolhido pela organização, mais comprometido ele ficará.

RC: 85330

Disponível em: https://www.nucleodoconhecimento.com.br/administracao/empresa-jr-log 
Diante do que foi visto é de se concordar que a Comunicação Interna é certamente, um instrumento estratégico para privilégios na empresa e, consequentemente, o sucesso da organização.

\section{REFERÊNCIAS}

APARECIDA, D. B. Imagem organizacional e contação de histórias: um estudo sobre o uso do storytelling como recurso estratégico de comunicação. Bauru, 2015.

BESSA C. J. de S. et al, Comunicação empresarial: como superar o desafio da distância com o uso da tecnologia móvel. Rio de Janeiro, 2018.

BUENO, W. da C. Comunicação empresarial: alinhando teoria e prática. Barueri, SP: Manole, 2014.

CHEMIN, B. F. Manual da univates para trabalhos acadêmicos: Planejamento, elaboração e apresentação. 3.ed.- Lajeado: Ed. da Univates, 2015.

CRUZ, L. O papel estratégico da comunicação nas organizações. 2016.

Disponível em: http://www.administradores.com.br/artigos/empreendedorismo/opapel-estrategico-da-comunicacao-nas-organizacoes/98324/. Acesso em: 14 de março de 2021.

FERNANDES, A. Comunicação interna nas empresas. 2020. Disponível em: https://www.pontotel.com.br/comunicacao-interna-nas-empresas/. Acesso em 09 de abril de 2021.

FLEURY, M. T. L.; WERLANG, S. R. C. Pesquisa aplicada: conceitos e abordagens. Edição: 2016. Anuário de pesquisa, 2016-2017.

FONSECA, R. C. V. Metodologia do trabalho científico. 1.ed., rev- Curitiba, PR: IESDE BRASIL, 2012.

RC: 85330

Disponível em: https://www.nucleodoconhecimento.com.br/administracao/empresa-jr-log 
GOULART, F. Funções da comunicação organizacional. 2015. Disponível em: https://www.rhportal.com.br/artigos-rh/funes-da-comunicao-organizacional/. Acesso em 09 de abril de 2021.

KOTLER, P. Administração de Marketing: a edição do novo milênio. 10.ed. São Paulo: Prentice Hall, 2014.

MATOS, G. G. de. Comunicação empresarial sem complicação. 3a Edição. Barueri - Sp: Manole, 2014.

MELLO, R. A. de. et al. Manual de produção acadêmica: tipos, normas e métodos. São Paulo: FMU, 2013.

PIZZANI, L. et al. A arte da pesquisa bibliográfica na busca do conhecimento. Rev. Dig. Bibl. Ci. Inf., Campinas, v.10, n.1, p.53-66, jul./dez, 2013.

ROBBINS, S. P. Comportamento organizacional. São Paulo: São Paulo, 2015.

SCHMIDT, A. C. M. Gestão de negócios. São Paulo: DCL, 2014.

SILVA, G. C. E. Comunicação organizacional e seus processos: um estudo de caso da companhia de transmissão de energia elétrica paulista. 2013. Disponível em: http://www.aems.edu.br/conexao/edicaoanterior/Sumario/2013/downloads/2013/3/40. pdf.

TIBURCIO, J. S. A comunicação interna como estratégia organizacional. 2013. Trabalho de Conclusão de Curso (Graduação em Administração) - Fundação Visconde de Cairu. Disponível em: http://www.cairu.br/riccairu/pdf/artigos/2_COMUNICACAO_INTERNA_ESTRATEGIA .$p d$

RC: 85330

Disponível em: https://www.nucleodoconhecimento.com.br/administracao/empresa-jr-log 
Enviado: Abril, 2021.

Aprovado: Maio, 2021.

RC: 85330

Disponível em: https://www.nucleodoconhecimento.com.br/administracao/empresa-jr-log 